\title{
DORMÊNCIA EM SEMENTES DE PARICARANA (Bowdichia virgilioides Kunth - FABACEAE - PAPILIONIDAE) ${ }^{1}$
}

\author{
OSCAR JOSÉ SMIDERLE²; RITA DE CÁSSIA POMPEU DE SOUSA ${ }^{3}$
}

\begin{abstract}
RESUMO - o trabalho foi realizado no Laboratório de Análise de Sementes da Embrapa Roraima, com o objetivo de estudar métodos para o alívio da dormência de sementes de paricarana. O delineamento experimental foi o inteiramente ao acaso com 4 repetições de 50 sementes. Os tratamentos foram: escarificação mecânica com lixa d'água; imersão em ácido sulfúrico (pa) por 5 e 10 minutos; imersão em álcool etílico por 5 e 10 minutos e testemunha, sem tratamento prévio das sementes. As sementes foram incubadas a $25^{\circ} \mathrm{C}$ no interior de placas plásticas 'gerbox', com papel "germitest” umedecido. Através de avaliações regulares, verificou-se os parâmetros porcentagem de germinação, porcentagem de sementes duras, índice de velocidade de germinação e porcentagem de plântulas normais ao final de 30 dias. A contagem diária das sementes germinadas foi feita durante 30 dias. Os resultados demonstraram que os tratamentos pré-germinativos promoveram a germinação de paricarana, sendo que a escarificação com ácido sulfúrico (5 minutos), revelou ser o método mais efetivo para o alívio da dormência desta espécie.
\end{abstract}

Termos para indexação: Bowdichia virgilioides, germinação, escarificação, permeabilidade do tegumento.

\section{SEED DORMANCY OF PARICARANA TREE (Bowdichia virgilioides Kunth) - FABACEAE - PAPILIONIDAE}

\begin{abstract}
This study was carried out at the Seed Laboratory of Embrapa Roraima, with the objective to study the alleviation of seed dormancy of the Paricarana tree (Bowdichia virgilioides). The experimental design was a completely randomized design with four replications of 50 seeds each. The treatments were: mechanic scarification with water sandpaper; sulfuric acid - pa (5 and 10 minutes), ethanol (5 and 10 minutes) and control. The seeds were placed in plastic boxes on moist paper and incubated at $25^{\circ} \mathrm{C}$ in a germinator. The parameters obtained were germination percentage, hard seed percentage, germination rate and percentage of normal seedlings at 30 days after sowing. The germinated seeds were counted daily for 30 days. Chemical scarification with sulfuric acid for 5 minutes was shown to be the most appropriate method for seed alleviation of this species.

Index-terms: Bowdichia virgilioides, germination, dormancy, scarification, tegument permeability.
\end{abstract}

\section{INTRODUÇÃO}

A utilização do teste de germinação é fundamental para o monitoramento da viabilidade das sementes em bancos de germoplasma, antes e durante o armazenamento. Todavia, o conhecimento atual sobre as técnicas de monitoramento é li-

\footnotetext{
${ }^{1}$ Aceito para publicação em 14/11/2003.

${ }^{2}$ Eng $^{\circ}$ Agr $^{\circ}$, Dr., Pesquisador; Embrapa Roraima, Cx. Postal 133, 69301970, Boa Vista, RR; ojsmider@cpafrr.embrapa.br

${ }^{3}$ Lic. Química, auxiliar de operações; Embrapa Roraima.
}

mitado, concentrando-se, principalmente, em plantas de interesse agrícola. Pouco se conhece acerca das condições para germinação da maioria das sementes de espécies silvestres (Heywood, 1989). Lotes de sementes que possuem algum tipo de dormência podem ter a sua viabilidade subestimada quando são obtidos baixos valores de porcentagem de germinação. Dessa forma, metodologias para a superação de dormência são importantes, particularmente, para o monitoramento da viabilidade de sementes (Ellis et al., 1985). A dormência é uma característica de relativa importância em lotes de sementes de espécies cultivadas, sendo, todavia, um 
dos problemas mais sérios na conservação de germoplasma de espécies silvestres, já que essas produzem freqüentemente sementes dormentes. A impermeabilidade do tegumento à água é um tipo de dormência bastante comum em sementes da família Leguminosae (Villiers, 1972). Para Rolston (1978), das 260 espécies de leguminosas examinadas, cerca de 85\% apresentavam sementes com tegumento total ou parcialmente impermeável à água.

Esse tipo de dormência pode ser superado através da escarificação, termo que se refere a qualquer tratamento que resulte na ruptura ou no enfraquecimento do tegumento, permitindo a passagem de água e dando início ao processo de germinação (Mayer \& Poljakoff-Mayber, 1989). Sob condições naturais, a escarificação pode se dar pelo aquecimento úmido ou seco do solo, ou por temperaturas alternadas, o que permitiria a água chegar ao interior da semente. Esse processo pode ocorrer, também, pela ação de ácidos, quando da ingestão das sementes por animais dispersores, além da ação dos microorganismos presentes no solo (Vazquez-Yanes \& Orozco-Segovia, 1993).

Em laboratório, foram desenvolvidos diversos métodos, visando a quebra da dormência por impedimento a entrada de água, como a escarificação mecânica e química, a embebição das sementes em água e tratamentos com altas temperaturas, sob condição úmida ou seca (Bewley \& Black, 1982; Bebawi \& Mohamed, 1985; Perez \& Prado, 1993).

De acordo com Eira et al. (1993), todos esses tratamentos apresentaram vantagens e desvantagens, de modo que cada um deles deve ser estudado, levando-se em conta, também, o custo efetivo e sua praticidade de execução. Além disso, as sementes podem apresentar diferentes níveis de dormência. Sendo assim, o método empregado deve ser efetivo na quebra da dormência, sem prejudicar as sementes com baixos níveis de dormência.

A busca de metodologias para análise de sementes florestais desempenha papel fundamental dentro da pesquisa científica e de interesse diversificado. O conhecimento dos principais processos envolvidos na germinação de sementes de espécies nativas é de vital importância para a preservação daquelas espécies ameaçadas e multiplicação dessas e das demais em programas de reflorestamento.

A Paricarana (Bowdichia virgilioides Kunth.) é uma árvore típica de áreas de savanas arborizadas em Roraima. Esta espécie é encontrada também nas regiões nordeste e centrooeste brasileiras, onde é conhecida pelos nomes populares de: sucupira-do-cerrado, sucupira-do-campo, angelim-amargoso, coração-de-negro (Almeida et al., 1998). Árvore de casca grossa e fendilhada atinge até 20 metros de altura, apresentando tronco com diâmetro máximo de 60 centímetros. Possuem folhas compostas, pinadas, com folíolos pubescentes. As pequenas flores, com corola lilás conferem um aspecto ornamental e apícola à árvore, que floresce entre os meses de outubro e dezembro. Os frutos são legumes, indeiscentes, achatados, contendo pequenas sementes com 3 a $5 \mathrm{~mm}$ de comprimento, apresentando coloração avermelhada (Lorenzi, 1992; Rizzini, 1990).

Possui madeira estriada pesada, de cerne pardo escuro, de alta durabilidade, dura, sendo empregada como dormentes, postes, cercas, embarcações e móveis de luxo. Pela sua elevada resistência ao fogo é muito utilizada em cercas de áreas de pastagem natural, em Roraima, sujeita a queimadas anuais. A infusão da entrecasca da paricarana é utilizada na medicina popular local para tratamento tópico de inflamações em geral.

Estudos de germinação de sementes vão auxiliar na produção de mudas para reflorestamento ou repovoamento de áreas onde ocorreu exploração intensa da espécie de forma extrativista, ou ainda, podem fomentar o uso desta árvore nativa em programas de arborização urbana de cidades localizadas em áreas de savana, com solos pobres e sujeitos a severas deficiências hídricas anuais. As sementes germinam entre 1 e 2 meses.

Levando-se em conta as características aparentes das sementes dessa espécie no que diz respeito à espessura do tegumento e sua dureza, o presente trabalho teve como objetivo selecionar tratamentos pré-germinativos em laboratório, que permitissem abreviar, aumentar e uniformizar a germinação das sementes de paricarana.

\section{MATERIAL E MÉTODOS}

O trabalho foi realizado no Laboratório de Análises de Sementes da Embrapa Roraima. As sementes foram colhidas e beneficiadas manualmente e armazenadas no laboratório em temperatura de $25^{\circ} \mathrm{C}$ e umidade relativa de $65 \%$.

Os tratamentos realizados foram: escarificação mecânica com lixa d'água por 1'; imersão em $\mathrm{H}_{2} \mathrm{SO}_{4}$ pa por 5'; imersão em $\mathrm{H}_{2} \mathrm{SO}_{4}$ pa por 10'; imersão em álcool etílico por 5'; imersão em álcool etílico por 10'; testemunha (sem tratamento).

Avaliações realizadas: Sementes duras: foram realizadas contagens diárias das sementes duras; Germinação: 200 sementes, depois de tratadas, foram semeadas em caixas plásticas (gerbox) contendo papel germitest umedecido 2,5 vezes 
seu peso com água deionizada e incubadas a $25^{\circ} \mathrm{C}$ no interior de germinador (Brasil, 1992). Contagens diárias foram realizadas durante 30 dias. Foi considerada germinada, a semente que apresentava comprimento radicular maior do que $2 \mathrm{~mm}$; Velocidade de germinação: foi obtida junto ao teste de germinação (Popinigis, 1985). O número de sementes germinadas em cada dia após a instalação do teste foi dividido pelo respectivo número de dias após a instalação do teste; Porcentagem de plântulas: ao final dos 30 dias foi obtido o número de plântulas normais, passiveis de se tornarem mudas para instalação de viveiro.

Utilizou-se delineamento experimental inteiramente ao acaso, com 04 repetições de 50 sementes por parcela. Os dados obtidos foram transformados em arc sen $(\mathrm{x} / 100)^{0,5}$.

\section{RESULTADOS E DISCUSSÃO}

Foram detectadas diferenças significativas para os caracteres porcentagem de sementes duras, porcentagem de germinação, porcentagem de plântulas e velocidade de germinação. Os coeficientes de variação estimados para os quatro caracteres oscilaram de 10,8\% a 14,8\% (Tabela 1).
Os tratamentos com $\mathrm{H}_{2} \mathrm{SO}_{4}$ e com lixa d’água apresentaram redução na porcentagem de sementes duras (Figura 1) e maiores porcentagens de germinação (Figura 2), diferindo do observado para as sementes tratadas com álcool e para a testemunha. Esses resultados mostram que a escarificação mecânica e o ácido sulfúrico foram mais eficazes em romper o tegumento das sementes de paricarana. Assim, a água foi absorvida pelas sementes, embebendo-as, o que desencadeou o processo de germinação e posterior emergência das plântulas.

A germinação de sementes aumentou de $21 \%$ para $79 \%$ com a escarificação com lixa d'água e de $21 \%$ para $90 \%$ na escarificação com $\mathrm{H}_{2} \mathrm{SO}_{4}$ por 5 minutos. Resultados semelhantes foram obtidos, com $\mathrm{H}_{2} \mathrm{SO}_{4}$, por Camargo \& Ferronato (1999) ao estudarem métodos de quebra de dormência. O T50 foi de 9 dias para o tratamento com ácido sulfúrico por 5 minutos e a lixa, e acima de 30 dias para o tratamento com álcool e testemunha. Esses resultados indicam benefícios dos tratamentos com $\mathrm{H}_{2} \mathrm{SO}_{4}$ e a escarificação mecânica para a multiplicação da espécie em estudo. Entre os dois tratamentos, destacamos a lixa por não ser perigosa ao manuseio pelo homem.

TABELA 1. Porcentagem de sementes embebidas, porcentagem de germinação e velocidade de germinação (VG) em sementes de paricarana obtidas com diferentes tratamentos para alívio de dormência. Boa Vista, RR. Embrapa Roraima, 2001.

\begin{tabular}{|c|c|c|c|c|}
\hline Tratamentos & $\begin{array}{c}\text { Sementes } \\
\text { embebidas }^{1} \\
(\%)\end{array}$ & $\begin{array}{c}\text { Germinação }^{1} \\
(\%)\end{array}$ & $\begin{array}{c}\text { Plântulas }{ }^{1} \\
\text { (\%) }\end{array}$ & $\mathbf{V G}^{2}$ \\
\hline Lixa d'agua 1' & $99 a$ & $79 a$ & $57 a$ & $10,2 \mathrm{a}$ \\
\hline $\mathrm{H}_{2} \mathrm{SO}_{4} 5$ & $100 \mathrm{a}$ & $90 a$ & $70 a$ & $10,3 a$ \\
\hline $\mathrm{H}_{2} \mathrm{SO}_{4} 10^{\prime}$ & $100 \mathrm{a}$ & $51 \mathrm{~b}$ & $31 \mathrm{~b}$ & 5,7 b \\
\hline Álcool 5’ & $66 \mathrm{~b}$ & 36 bc & $19 \mathrm{~b}$ & 1,8 \\
\hline Álcool 10’ & $65 \mathrm{~b}$ & 30 bc & $29 \mathrm{~b}$ & 1,6 \\
\hline Testemunha & $54 \mathrm{~b}$ & $21 \quad \mathrm{c}$ & $17 \mathrm{~b}$ & 0,9 \\
\hline CV (\%) & 12,4 & 14,8 & 14,6 & 10,8 \\
\hline
\end{tabular}

* Na coluna, médias seguidas de letras distintas diferem entre si pelo teste de Duncan a 5\% de probabilidade de erro.

${ }^{1}$ Dados em porcentagem.

2 Dados na forma de índice. 


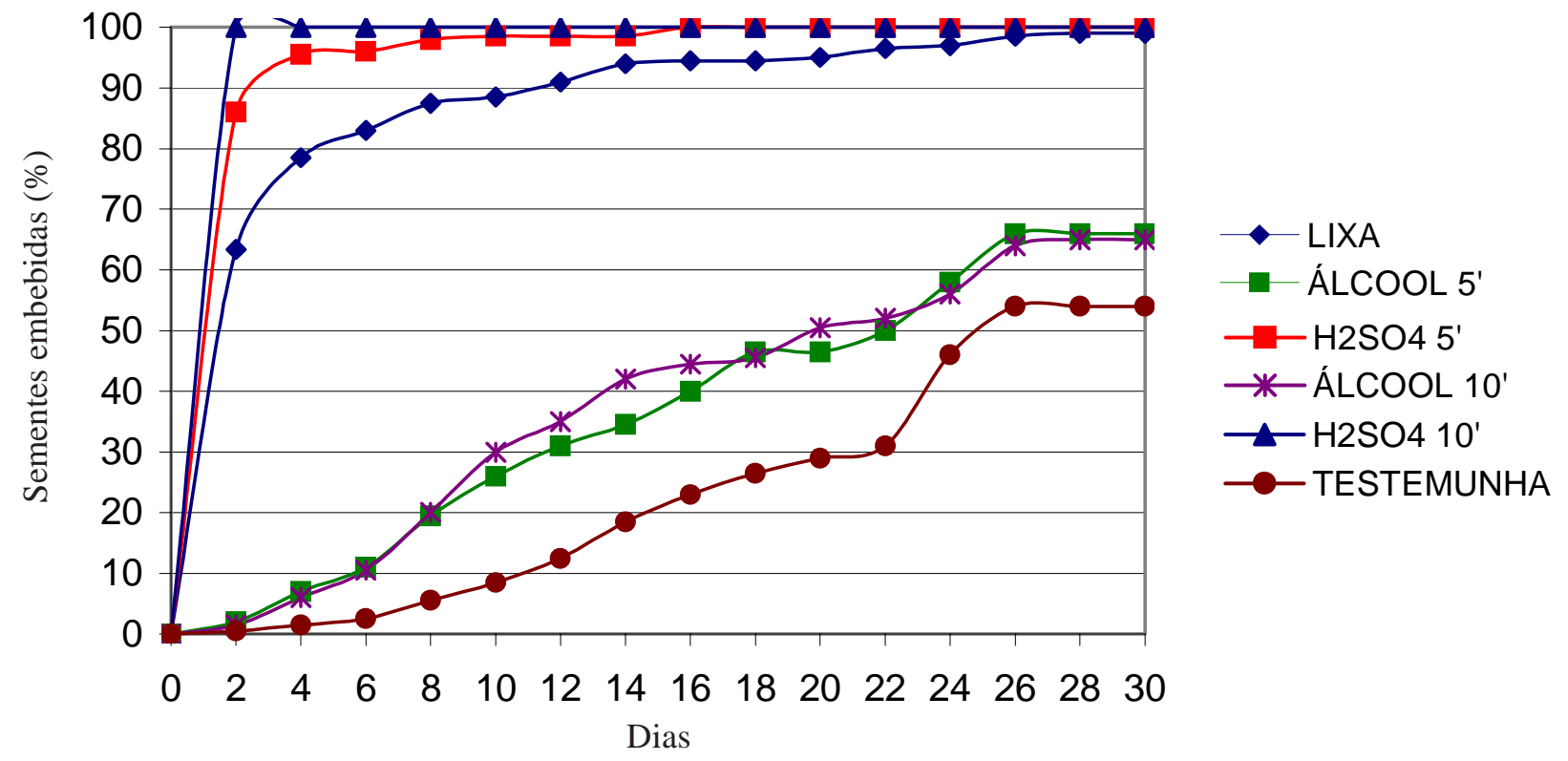

FIG. 1. Porcentagem de sementes embebidas de paricarana, (Bowdichia virgilioides Kunth) após realizados diferentes tratamentos de escarificação. Boa Vista, RR. Embrapa Roraima, 2001.

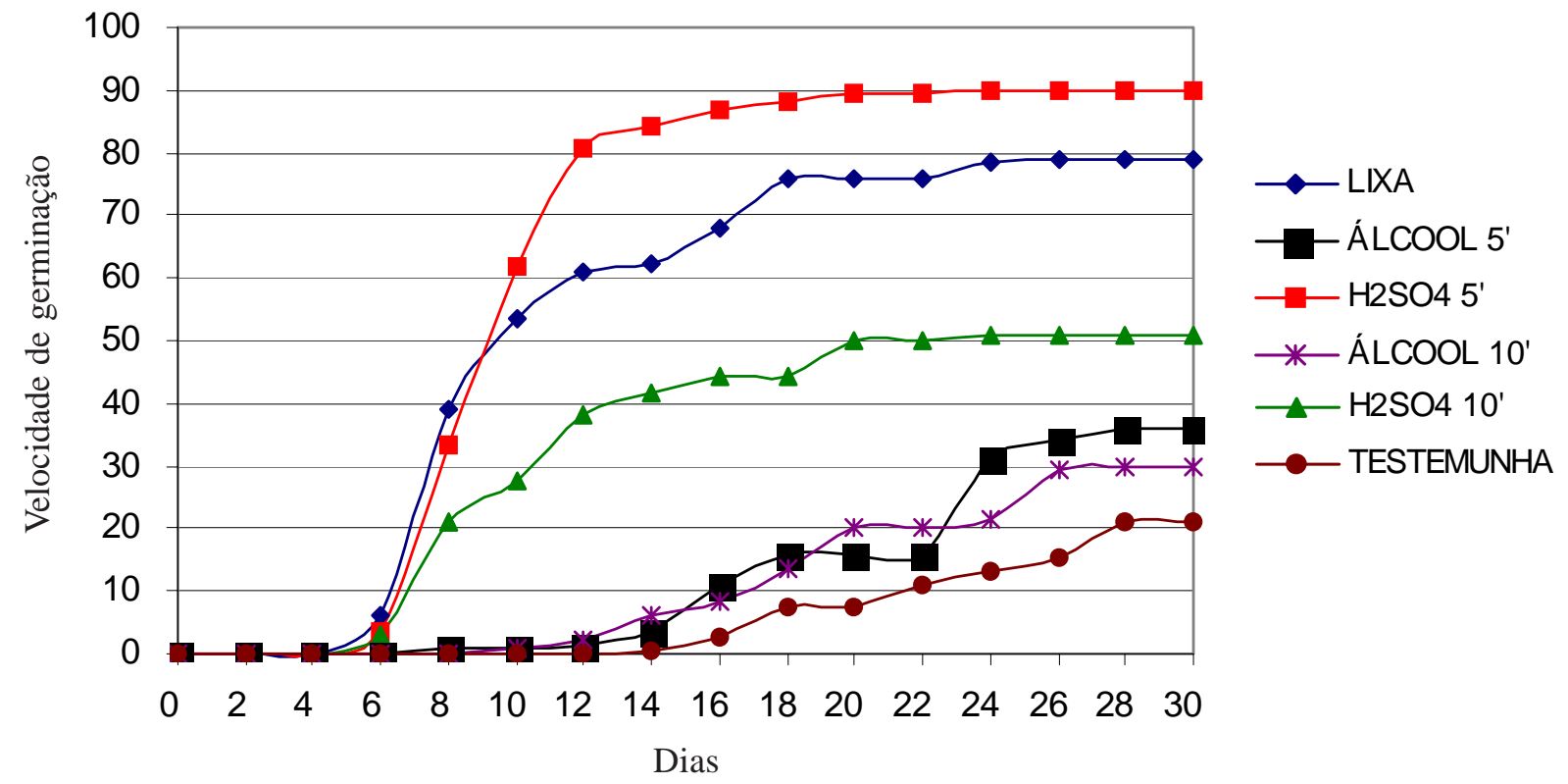

FIG. 2. Velocidade de germinação de sementes de paricarana, (Bowdichia virgilioides Kunth) após os diferentes tratamentos de escarificação. Boa Vista, RR. Embrapa Roraima, 2001. 


\section{CONCLUSÃO}

Dentre os tratamentos realizados, a escarificação química com $\mathrm{H}_{2} \mathrm{SO}_{4}$ (5 minutos), foi o método mais apropriado para o alívio da dormência, e conseqüentemente o aumento na porcentagem de germinação das sementes de paricarana.

\section{REFERÊNCIAS}

ALMEIDA, S.P.; PROENÇA, C.E.B.; SANO, S.M.; RIBEIRO, J.F. Cerrado: espécies vegetais úteis. Planaltina: Embrapa-CPAC, 1998. 464p.

BASTOS, G.Q.; NUNES, R.S.; CRUZ, G.M.F. Reavaliação de quebra de dormência em sementes de algaroba (Proposis juliflora (SW) DC). Revista Brasileira de Sementes, v.14, p.1720, 1992.

BEBAWI, F.F.; MOHAMED, S.M. The pretreatment of seeds of six Sudanese Acacias to improve their germination response. Seed Science and Technology, v.13, p.111-119, 1985.

BEWLEY, J.D.; BLACK, M. Physiology and biochemistry of seeds. Berlim: Springer-Verlag, 1982. v.1, 540p.

BRASIL. Ministério da Agricultura e Reforma Agrária. Regras para análise de sementes. Brasília: SNAD/DNDV/CLAV, 1992. 365p.

CAMARGO, I.P.; FERRONATO, A. Comparação de métodos de superação da dormência em sementes de sucupira-preta (Bowdichia virgilioides H.B.K. - Fabaceae-Papilionidae). Curitiba: Informativo ABRATES, v.9, n.1/2. 1999. p.170.

EIRA, M.T.S.; FREITAS, R.W.A.; MELLO, C.M.C. Superação da dormência de sementes de Enterolobium contortisiliquum (VELL.) Morong.-Leguminosae. Revista Brasileira de Sementes, v.15, p.177-182, 1993.

ELLIS, R.H.; HONG, T.D.; ROBERTS, E.H. Handbook of seed germination for genebanks. Rome: IBPGR, 1985. v.2, p.211-667.
HEYWOOD, V.H. Estratégias dos jardins botânicos para a conservação. Rio de Janeiro: Jardim Botânico do Rio de Janeiro, 1989. 69p. Tradução de Patrícia O. Mousinho, Luiz A.P. Gonzaga e Dorothi S.D. Araújo.

KOBMOO, B.; HELLUM, A.K. Hot water and acid improve germination of Cassia siamea Britt seeds. The Embryon, v.1, p.2733, 1984.

LABOURIAU, L.G.; VALADARES, M.B. On the germination of seeds of Calotropis procera. Anais da Academia Brasileira de Ciências, Rio de Janeiro, v.48, p.174-186, 1976.

LORENZI, H. Árvores brasileiras. Manual de identificação e cultivo de plantas arbóreas nativas do Brasil. Nova Odessa, SP. Ed. Plantarum, 1992. 352p.

MARTINS, C.C.; CARVALHO, N.M.; OLIVEIRA, A.P. Quebra de dormência de sementes de sabiá (Mimosa caesalpiniaefolia Benth). Revista Brasileira de Sementes, v.14, p.5-8, 1992.

MAYER, A.M.; POLJAKOFF-MAYBER, A. The germination of seeds. Oxford: Pergamon Press, 1989. 270p.

PEREZ, S.C.J.G.; PRADO, C.H.B.A. Efeitos de diferentes tratamentos pré-germinativos e da concentração de alumínio no processo germinativo de sementes de Copaifera langsdorffii Desf. Revista Brasileira de Sementes, v.15, p.115-118, 1993.

POPINIGIS, F. Fisiologia da semente. Brasília: AGIPLAN, 1985. 289p.

RIZZINI, C. T. Árvores e madeiras úteis do Brasil. Manual de dendrologia brasileira. São Paulo, Edgard Blücher, 2 ed. 1990. 296p.

ROLSTON, M.P. Water impermeable seed dormancy. The Botanical Review, v.44, p.365-396, 1978.

VAZQUEZ-YANES, C.; OROZCO-SEGOVIA, A. Patterns of seed longevity and germination in the tropical rainforest. Annual Review of Ecology and Systematics, v.24, p.69-87, 1993.

VILLIERS, T.A. Seed dormancy. In: KOZLOWSKY, T.T. (Ed.). Seed biology. New York: Academic Press, 1972. v.2, p.220-282. 